\title{
Editor Welcomes New Year
}

Dr. Myers and I are delighted to begin a new year of publication of the International Journal of Integrative Pediatrics and Environmental Medicine (IJIPEM).

In the past, we published on a variety of topics that impact a child's life. Most of our publications were original research papers. We are also open to publish reviews, case reports, and letters on topics centered on modifiable factors that determine child health.

During the brief existence of IJIPEM we published on such important topics as smoking exposure, children's spirituality, PTSD, and living with siblings with chronic conditions. We had a paper about the use of Google technology in estimating disease exposure in Asia and covered all ages from pre-term newborns to adolescents.

We are proud to see that our authors are from three continents and we are looking forward to expanding our geography. Candace Myers PhD, the IJIPEM Editor-in-Chief, guided and helped all authors, which allowed the journal to publish high quality manuscripts. We appreciate our Editorial Board and every expert who helped us with the peer-review process.

We hope to continue to keep our high standard of publication with the goal to be indexed on PubMed and other search resources. We welcome submissions from medical practices and clinical research and promise to expedite all publications with rapid communications between editors, authors, and peerreviewers. If English is an author's second language, we will personally work with an author to clean up grammar and wording before sending the article out for review.

Visit IJIPEM.COM for more information about the new journal. We hope our readers and authors will be pleased with our service.

Sincerely yours,

Tetyana L. Vasylyeva MD PhD Dsc Managing Editor International Journal of Integrative Pediatrics and Environmental Medicine tetyana.vasylyeva@ijipem.com tetyana.vasylyeva@ttuhsc.edu 